\title{
Variables affecting desmoid tumor risk in Familial Adenomatous Polyposis: A critical review
}

\author{
Campos FG*, Bustamante-Lopez L, Kotze PG and Martinez CAR \\ Departamento de Gastroenterología, Hospital das Clínicas, Universidad de São Paulo, Brazil
}

\begin{abstract}
Introduction: Familial Adenomatous Polyposis (FAP) is a genetic disorder that predisposes to colorectal cancer and many other extracolonic manifestations. Among them, desmoid disease is considered a great challenge and a major source of morbidity in these patients. The aim of the present manuscript is to evaluate the role of many clinical and surgical variables potentially involved in desmoid risk after prophylactic colectomy. Methods: we have searched case series, observational studies, retrospective studies, meta-analyses and systematic reviews (1990 to 2020) dealing with incidence and risk factors for desmoid disease after FAP surgical treatment. Results: desmoid disease may develop in approximately 10-20\% of FAP patients leading to complications and mortality. Frequency and risk of desmoid risk have been associated with clinical and surgical variables not always dependent on surgeon control. Female sex, family history of desmoid disease, surgical trauma (reoperations and complications), specific genotypes and timing of surgery have demonstrated some influence on desmoid rates. Otherwise, type of surgery and surgical approach (open or laparoscopic) are not uniformly correlated with this risk. Conclusions: the information extracted from the literature suggests that our ability to influence desmoid disease development is limited. Integration of clinical and genetic data may help to define a higher risk subgroup of patients who may eventually benefit from specific preventive recommendations and postponed surgical intervention.
\end{abstract}

\section{Introduction and statement of the problem}

Familial adenomatous polyposis (FAP) is an autonomic hereditary dominant disease associated with a great risk for colorectal cancer (CRC) and different extra-intestinal manifestations [1]. Ideally, at risk or symptomatic patients should be screened during the second decade of life, and surgery indicated between 18-25 years of age for the majority of patients [2-4].

After prophylactic colectomy, desmoid tumors (DT) and duodenal carcinoma are considered the main reasons for mortality in this group of patients [5]. As a possible life-threatening condition, DT diagnosis is challenging for both the patient and surgeon. Development of these tumors is a consequence of the triggering effects of surgical trauma, being diagnosed some years after colectomy [6].

When dealing with DT, chances of therapeutic success are variable, not predictable and inconsistent. The multimodal management of patients with desmoid disease is based on staging, and includes nonsteroidal anti-inflammatory drugs (NSAIDS), hormonal therapy, chemotherapy, target therapy with tyrosine kinase inhibitors (Imatinib, Sorafenib, Pazopanib) and surgical resection [7]. Nowadays, it is well accepted that surgery may be reserved only for specific emergency situations and abdominal wall lesions [8].

Sporadic DT occurring in the general population represent 85 $90 \%$ of these tumors. The risk of desmoid disease in FAP is $800-1000$ folds greater than what is observed in the general population, and this unfortunate outcome has been described in approximately $10-15 \%$ of FAP patients $[9,10]$.

In a different perspective, FAP-associated DT are more often intra-abdominal, and resection of mesenteric desmoids may lead to important surgical complications and recurrence [6]. Consequently, preventive measures should be advised whenever possible.
Thus, the presented critical review aimed to discuss clinical, molecular and surgical variables identified as risk factors for desmoid disease, aiming to formulate strategies that could help to prevent this severe feature of the syndrome. This objective was accomplished by reviewing the pertinent literature and by searching articles that analysed any factor eventually associated with desmoid disease risk.

\section{Methods}

The present manuscript was written on the basis of a meticulous analysis of articles published from 1990 to 2020 in English language. Sources of search were restricted to Medline and PubMed. Specific keywords combinations included "Familial Adenomatous Polyposis", "desmoid tumors", "desmoid disease", "colorectal cancer", "surgical purpose", "Ileal pouch-anal anastomosis", "ileorectal anastomosis", "laparoscopic surgery", "laparoscopic approach", "laparoscopic resection", "open surgery”, “open approach", "open resection”, "hereditary disease", "risk factor", "minimally invasive surgery".

The initial search (FAP and desmoid) identified 718 articles. After establishing filters for language and Medline, there were obtained 518 results. An initial review of the titles led us to exclude other 420 articles. After a more detailed review of the remaining 98 manuscripts, we finally separated 40 articles (case series, peer-reviewed observational studies,

${ }^{*}$ Correspondence to: Fabio Campos, Departamento de Gastroenterología, Hospital das Clínicas, Universidad de São Paulo, Brazil, E-mail: fgmcampos@ terra.com.br

Key words: familial adenomatous polyposis, desmoid tumors, risk factor, laparoscopic surgery, restorative proctocolectomy, ileorectal anastomosis

Received: February 15, 2021; Accepted: February 26, 2021; Published: March 05, 2021 
retrospective studies, meta-analyses, systematic reviews) to serve as our source material (Figure 1). Included articles should important aspects regarding desmoid etiology and analysis of clinical and surgical risk factors associated with the tumor development.

\section{Desmoid disease: Incidence and characteristics}

Table 1 presents demographic features of many case series regarding the diagnosis of FAP-related desmoid tumors. Reports from many countries with different numbers show that almost $20 \%$ of FAP patients may develop DT during lifetime. Differences in incidence are attributed to different factors. Certainly, diagnostic criteria are one of the most important of them.

DT may be found as small plaques during surgery in approximately $3-4 \%$ of patients and their identification depends on an active search of the surgeon trying to identify these lesions. Moreover, a greater number and complex cases may be referred to centers with greater experience in managing DT.

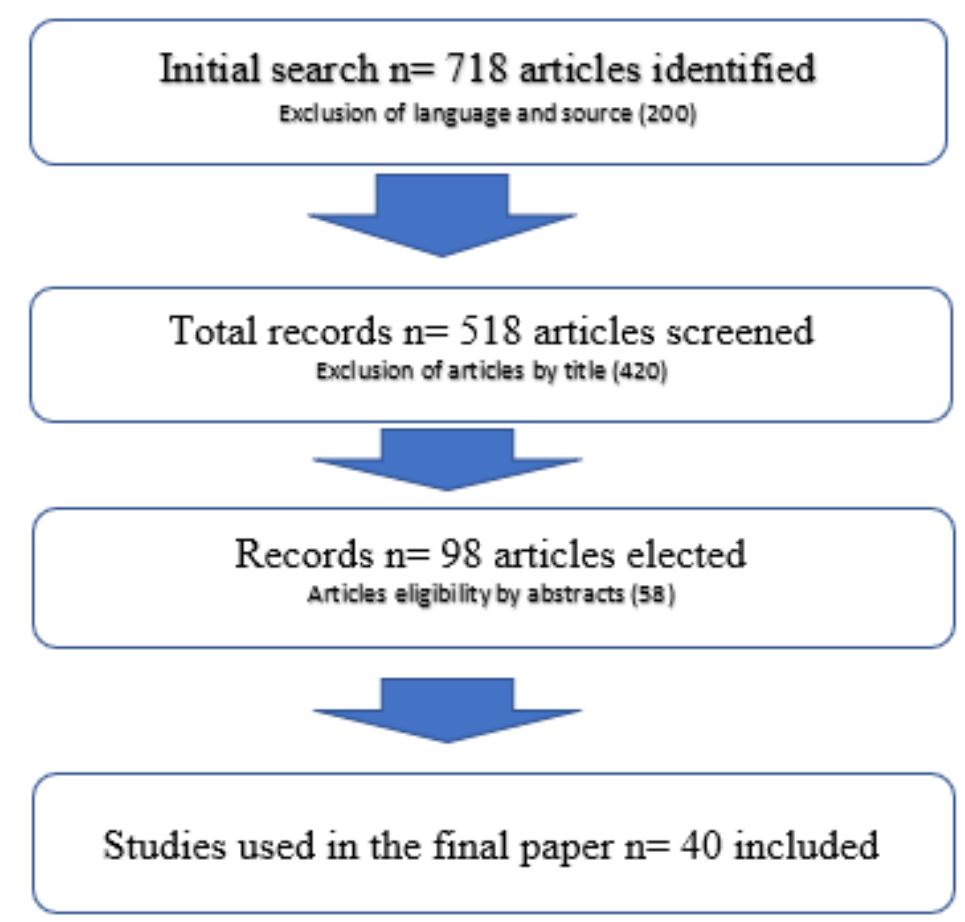

Figure 1. Literature search flow sheet

Table 1. Demographic features of literature series focusing postoperative desmoid tumors in familial adenomatous polyposis patients

\begin{tabular}{|c|c|c|c|c|c|c|c|}
\hline Author & Country & FAP & Desmoid N (\%) & Period (years) & Gender F:M & DT Median Age (y) & Interval (y) \\
\hline Gurbuz, 1994 & USA & 825 & $83(10.1 \%)$ & 21 & 1.4 & 31 & 9 \\
\hline Heiskanen, 1996 & Finland & 202 & $29(14.3 \%)$ & 57 & 1.4 & - & 3.2 \\
\hline Hizawa 1997 & Japan & 49 & $6(12.2 \%)$ & 24 & 5 & 31 & 3.9 \\
\hline Bertario 2001 & Italian & 897 & $107(11.9)$ & 38 & 1.5 & 33 & 3.5 \\
\hline Sturt 2004 & England & 320 & $50(15.6 \%)$ & - & 1.9 & - & - \\
\hline Vogel 2005 & USA & 90 & $12(13.3 \%)$ & 13 & 1.1 & - & 4,0 \\
\hline Koh 2006 & Singapore & 205 & $23(11.2 \%)$ & 17 & 1.3 & - & 3 \\
\hline Durno 2007 & Canada & 887 & $121(13.6 \%$ & 25 & 1.3 & 32 & - \\
\hline Koh 2007 & Singapore & 205 & $23(11.2 \%$ & 25 & 1.3 & - & 2.9 \\
\hline Lefevre 2008 & France & 442 & $50(11.3 \%)$ & 21 & 1 & 32 & - \\
\hline $\begin{array}{l}\text { Nieuwenhuis } \\
2008 \\
2011^{*}\end{array}$ & $\begin{array}{l}\text { Holand } \\
5 \text { countries }\end{array}$ & $\begin{array}{c}735 \\
2260\end{array}$ & $\begin{array}{c}66(8.9 \%) \\
387(17.1 \%)\end{array}$ & $\begin{array}{c}20 \\
- \\
\end{array}$ & $\begin{array}{l}0.9 \\
1.2 \\
\end{array}$ & $\begin{array}{l}33 \\
31 \\
\end{array}$ & - \\
\hline Sinha $2010^{* *}$ & England & 558 & $49(9.0 \%)$ & 83 & 1.6 & 27 & 2.5 \\
\hline Vitellaro 2014 & Italy & 672 & $101(15.0 \%)$ & 8 & 1.6 & - & - \\
\hline Saito $2016 *$ & Japan & 277 & $39(14.1 \%)$ & - & 1.8 & - & 2.5 \\
\hline Walter 2017 & France & 180 & $31(17.2 \%)$ & 19 & 1.8 & 33 & 4.7 \\
\hline Inoue 2017 & Japan & 303 & $33(10.9 \%)$ & - & 1.4 & - & - \\
\hline
\end{tabular}

*multicenter study ** only intra-abdominal desmoids 
Usually, one in six FAP patients may be diagnosed with DT after a postoperative period of $2-5$ years, so diagnosis is also dependent on length of follow-up [11-13]. Furthermore, clinical and surgical variables may eventually influence the pertinent data. Another interesting point is that the number of reported DT may vary according to reported location of these tumors. Differently from DT occurring in the general population, most FAP-associated DT are diagnosed within the abdominal cavity, usually the mesentery. These intra-abdominal desmoids may infiltrate the bowel, major vessels and ureter, eventually causing complications and death $[5,14,15]$.

\section{Risk factors for desmoid disease}

Many case series, reviews and metanalysis have tried to analyze the influence of clinical and surgical variables on DT formation after surgery. From these publications, female gender, positive family history, genotype and previous abdominal surgery have been identified as non-modifiable DT risk factors [12,16-20]. On the other hand, associated CRC, purpose of surgery, type of operative procedure and surgical approach demonstrated controversial results. On this matter, previous abdominal operations and postoperative complications with reoperations have deserved renewed attention.

Table 2 demonstrates a brief summary of the many factors already linked to FAP-DT risk in published series, reviews and meta-analysis.

\section{Clinical features affecting $\mathrm{dt}$ incidence}

\section{Female gender}

Female sex has been classically considered a relevant risk factor for DT, giving support for the idea of possible hormonal influence on tumor growth [12,18,21-24]. As seen in Table 1, this finding is substantiated on the analysis of female preponderance in most case series described in the literature.

A Canadian study showed that women undergoing an early operation (before 18 years of age) were 2.5 times more likely to develop DT [17], a similar finding also reported in Italy [25]. Meta-analysis and multi-center studies including thousands of patients also reassured the female gender as an independent risk factor $[19,26]$.

\section{Family history and genotype}

Due to the hereditary nature of the disease, analysis of the real influence of familial clustering on DT risk is not simple. However, this association has been identified in classical studies containing data from important institutions, in which evaluation of large FAP cohorts revealed an 7-9 folds increased risk if a first-degree relative is also identified with DT $[19,21,22,27]$. Some believe that this association is even independent from patient's genotype [18].

Recent publications suggest that any mutation throughout the gene may result in desmoid disease $[16,22]$. Besides that, a greater chance has been credited to specific mutations in APC gene, such as 3'distal (codons 1310 to 2011) [25,28,29] and 5'region (codons 543-713) [30]. Features of higher incidence, severity and poor outcome meet association with 3'mutations of codon 1399 [16]. Specially for intraabdominal lesions, this correlation with mutation site seem to be less relevant, with a greater emphasis on disease severity [13,23,31].

\section{Surgical issues related to desmoid disease development}

\section{Surgical trauma}

FAP-associated desmoid disease is commonly associated with trauma after any type of operation or approach $[16,18]$. In this context, previous abdominal surgery has been constantly incriminated, although the mechanism guiding this process remains unclear [26]. In an analysis of ten publications (1965-2009), a 3-times greater chance of DT was reported in those with previous surgical trauma [18].

Doubts regarding a triggering factor related to tissue trauma and genotype have generated many debates in the past [22]. This fact generated the strategy to postpone prophylactic surgery especially in those reporting other family history of DT or having 3'APC mutations on genotype. However, these patients should preferably have an attenuated phenotype and also be compliant with endoscopic surveillance. These selected patients may also benefit from chemoprevention with celecoxib [18].

\section{Do surgical choices and decisions affect DT incidence?}

The possibility of reducing the chances of DT by modifying surgical strategy represent an important fraction of surgeons' concerns for a long time. Since the surgical trauma triggers the chances of desmoid growth, defenders of this idea thought that establishing a different timing or selecting a certain surgical procedure or approach could have a great impact on postoperative outcomes.

Usually, FAP patients are treated either through ileorectal anastomosis (IRA) or restorative proctocolectomy (RPC) [32,33]. Thus, it is of great interest to evaluate if the extension of surgical trauma to the pelvis could influence such risk. In Table 3 we present literature data comparing DT rates after RPC or IRA. Some series reported worst results after RPC, considering that the ileoanal anastomosis would hypothetically generate mesenteric tension, what could lead to development of DT [34]. However, this finding was not universally accepted $[18,23,31]$.

Table 2. Clinical risk factors for desmoid tumors development in familial adenomatous polyposis patients

\begin{tabular}{|c|c|c|}
\hline Authors & Country & Identified risk factors \\
\hline Bertario 2001 & Italy & female, family history, osteomas, genotype \\
\hline Elayi 2009 & USA & $\begin{array}{c}\text { Family history and genotype* } \\
\text { female, extracolonic manifestations, family history, genotype }\end{array}$ \\
\hline Niewenhuis 2011 & $\begin{array}{c}\text { 5 countries } \\
\text { female, genotype and family history } \\
\text { female, genotype and family history } \\
\text { (OR 4.37 for mutations 3'of 1399) }\end{array}$ & $\begin{array}{c}\text { United Kingdom } \\
\text { meta-analysis }\end{array}$ \\
\hline Sinha 2010 Sinha 2011 & France & Proctocolectomy \\
\hline Walter 2017 & Japan & female, proctocolectomy \\
\hline Saito 2018 & Italy & Genotype* \\
\hline Vitellaro & (3.8 HR mutation distal to codon 1400) &
\end{tabular}

Risk factor for desmoid disease, but no association for intra-abdominal desmoids 
Appreciation of the results reveals only two publications clearly demonstrating a greater chance of desmoid disease after RPC [12,35]. In the Japanese multicenter study [12], the initial evaluation of 47 DT patients (14.7\% of $319 \mathrm{FAP})$ coming from 23 centers was reduced to a final count of 39 DT (in 277 FAP) due to "instances of incomplete data". Only $64 \%$ of those patients were diagnosed with intra-abdominal DT and 23\% were located only in the abdominal wall. However, the authors don't present details regarding additional incisions to perform specimen extraction or anastomosis, which could differentiate both groups (RPC and IRA) in terms of abdominal trauma. A similar finding was reported in the French study [35].

Conversely, analysis of a large international cohort from five European countries revealed no difference in 2260 FAP patients (387 DT) (26). Similar results were described in a meta-analysis of 1260 patients [36].

At the same point, comparison of different surgical approaches (open vs. laparoscopic surgery) may be another important information for the surgeon. Indication of laparoscopic approach to treat FAP patients have been associated with good outcomes in this group of young patients $[32,37]$. Furthermore, due to the recognized role of trauma in DT formation, one could imagine that the open approach would be associated with worse results.

However, in a comparison between previous reports (Table 4), laparoscopy seemed to be advantageous in only one study that revealed a 6.8 hazard ratio associated with open surgery [25]. However, it is important to emphasize the existence of one Japanese study that compared only patients undergoing IRA [19]. Subsequent DT development occurred in $4 \%$ vs. $16 \%$ of those after a laparoscopic approach.

Another surgical variable that may influence DT development is the timing definition for surgical treatment. In FAP patients, colorectal cancer is rare before 20 years of age, although screening may start during the second decade of life. But surgical indication during this phase may be an option in symptomatic patients, with increasing polyp count, with non-resectable risk polyp or with family history of severe phenotype [38]. Most commonly, prophylactic surgical resection is preferably performed between 18-25 years of age in patients fully informed and mentally mature $[3,39,40]$.

The possibility of developing desmoid disease is considered a motive to alter this schedule [22]. In Table 1 describes that most DT are diagnosed at the third decade of life. Usually, the desmoid disease develops around 24-36 months after surgery $[5,18,25]$. Thus, a common sense recommends that patients at risk for any reason should have their surgery postponed as much as possible.

The group with greater risk should include women, patients referring other cases of DT in the family, those with a propense phenotype and maybe patients that had already undergone multiple operative procedures.

In an interesting Canadian study, Durno et al [17] demonstrated that female patients having an early (before 18 years of age) colectomy are at significantly greater risk of developing a desmoid tumor than those operated later in their lives. Similarly, other Japanese series also reported favorable results regarding DT development and patients older than 30 years of age at surgery [12].

All the issues discussed here reveal how challenging desmoid disease may be in therapeutic algorithms. Although some risk groups may exist, their precise identification still requires refinement criteria. Adoption of specific surgical planning such as minimal invasive approaches with the aim to prevent development of DT haven't demonstrated effectiveness so far. Similarly, the choice of a less extensive procedure (ileorectal anastomosis) doesn't seem to reduce the risk.

On contrary, postponing operative treatment accordingly to colorectal cancer risk evaluated through endoscopic surveillance may be a safe decision in female patients with family history of desmoids, with multiple operations or exhibiting a genotype that could induce desmoid formation after trauma.

Currently, the present scenario shows that there is an urgent need for the development of pharmacological agents (anti-estrogens, antiinflammatory, tyrosine kinase inhibitors and others) that could be effective and safe to prevent and treat these patients.

Table 3. Incidence of desmoid tumors in patients undergoing restorative proctocolectomy (RPC) or total colectomy with ileal-rectal anastomosis (IRA) to treat familial adenomatous polyposis

\begin{tabular}{|c|c|c|c|c|}
\hline Authors & FAP (DT\%) & RPC & IRA & $\mathbf{p}$ \\
\hline Vogel 2005 & $90(13.3 \%)$ & $17.8 \%$ & $8,9 \%$ & $\mathrm{P}=0.35$ \\
\hline Gega 2006 & $120(9.1 \%)$ & $12.6 \%$ & $13 \%$ & $\mathrm{P}=0.5$ \\
\hline Sinha $2010 \#$ & $558(9.0 \%)$ & $3.8 \%$ & $5.1 \%$ & $\mathrm{P}=0.6$ \\
\hline Nieuwenhuis $2011 *$ & $2260(17 \%)$ & $10.1 \%$ & $11.1 \%$ & $\mathrm{P}=0.53$ \\
\hline Vitellaro 2014 & $672(15.0 \%)$ & $17.3 \%$ & $15.6 \%$ & $\mathrm{P}=0.20$ \\
\hline Saito 2016 * & $277(14.1 \%)$ & $16.6 \%$ & $7.4 \%$ & $P=0.03$ \\
\hline Walter $2017 *$ & $180(17.2 \%)$ & $25.0 \%$ & $12 \%$ & $P=0.02$ \\
\hline XIE $2020 * *$ & $1072(10.5 \%)$ & $11.8 \%$ & $9.5 \%$ & $\mathrm{P}=0.8$ \\
\hline
\end{tabular}

*Multicenter study; ** meta-analysis, FAP = familial adenomatous polyposis; DT = desmoid tumors; RPC = restorative colectomy; IRA = ileal-rectal anastomosis; \# only intra-abdominal DT

Table 4. Literature series reporting desmoid tumors rates in familial adenomatous polyposis patients treated by open or laparoscopic approaches

\begin{tabular}{|c|c|c|c|}
\hline Authors & FAP (DT\%) & LAP & OPEN \\
\hline Vogel 2005 & $90(13.3 \%)$ & $15.6 \%$ & $11.2 \%$ \\
\hline Vitellaro 2014 & $672(15.0 \%)$ & $4.3 \%$ & $13.0 \%$ \\
\hline Ueno $2016^{*}$ & $303(13.5 \%)$ & $12.8 \%$ & $19.1 \%$ \\
\hline Saito $2016^{*}$ & $277(14.1 \%)$ & $15.6 \%$ & 0.17 \\
\hline Walter 2017 & $180(17.2 \%)$ & $16.8 \%$ & $0.3 \%$ \\
\hline
\end{tabular}

* multicenter study

LAP = laparoscopic surgery; OPEN = laparotomy (conventional) 


\section{Funding}

No funding was received for preparing this guideline.

\section{Conflict of interests}

the authors have declared no competing interests related this material.

\section{References}

1. Campos FG, Habr-Gama A, Kiss DR, Atuí FC, Katayama F, et al. (2003) Extracolonic manifestations of familial adenomatous polyposis: incidence and impact on the disease outcome. Arq Gastroenterol 40: 92-98. [Crossref]

2. Vasen HF, Moslein G, Alonso A, Aretz S, Bernstein I, et al. (2008) Guidelines for the clinical management of familial adenomatous polyposis (FAP). Gut 57: 704-713.

3. Möslein G (2016) Surgical considerations in FAP-related pouch surgery: Could we do better? Fam Cancer 15: 457-466.

4. Campos FG (2014) Surgical treatment of familial adenomatous polyposis: dilemmas and current recommendations. World J Gastroenterol 20: 16620-16629.

5. Campos FG, Martinez CA, Novaes M, Nahas SC, Cecconello I (2015) Desmoid tumors: clinical features and outcome of an unpredictable and challenging manifestation of familial adenomatous polyposis. Fam Cancer 14: 211-219.

6. Tayeb TC, Parc Y, Andre T, Ataz DLT (2020) Familial adenomatous polyposis, desmoid tumors and Gardner syndrome. Bull Cancer 107: 352-358.

7. Inoue $\mathrm{Y}$, Ishida H, Ueno H, Kobayashi H, Yamaguchi T, et al. (2017) The treatment of desmoid tumors associated with familial adenomatous polyposis: the results of a Japanese multicenter observational study. Surg Today 47: 1259-1267. [Crossref]

8. Bonvalot S, Tzanis D, Bouhadiba T (2020) Desmoid tumors: Are there still any surgical indications? Bull Cancer 107: 364-370.

9. Koh PK, Loi C, Cao X, Cheah PY, Ho KS (2007) Mesenteric desmoid tumors in Singapore familial adenomatous polyposis patients: Clinical course and genetic profile in a predominantly Chinese population. Dis Colon Rectum 50: 75-82.

10. Lefevre JH, Parc Y, Kernéis S (2008) Risk factors for development of desmoid tumours in familial adenomatous polyposis. Br J Surg 95: 1136-1139.

11. Hizawa K, Iida M, Mibu R, Aoyagi K, Yao T (1997) Desmoid tumors in familial adenomatous polyposis/Gardner's syndrome. J Clin Gastroenterol 25: 334-337.

12. Saito Y, Hinoi T, Ueno H, Kobayashi H, Konishi T, et al. (2016) Risk factors for the development of desmoid tumor after colectomy in patients with familial adenomatous polyposis: multicenter retrospective cohort study in Japan. Ann Surg Oncol 23: 559565 .

13. DE Marchis ML, Tonelli F, Quaresmini D, Lovero D, Della-Morte D, et al. (2017) Desmoid tumors in familial adenomatous polyposis. Anticancer Res 37: 3357-3366.

14. Campos FG, Perez RO, Imperiale AR, Seid VE, Nahas SC (2010) Evaluating causes of death in familial adenomatous polyposis. J Gastrointest Surg 14: 1943-1949.

15. Gega M, Yanagi H, Yoshikawa R, Noda M, Ikeuchi H, et al. (2006) Successful chemotherapeutic modality of doxorubicin plus dacarbazine for the treatment of desmoid tumors in association with familial adenomatous polyposis. J Clin Oncol 24 : 102-105.

16. Church J, Xhaja X, LaGuardia L, O’Malley M, Burke C (2015) Desmoids and genotype in familial adenomatous polyposis. Dis Colon Rectum 58: 444-448. [Crossref]

17. Durno C, Monga N, Bapat B, Berk T, Cohen Z (2007) Does early colectomy increase desmoid risk in familial adenomatous polyposis? Clin Gastroenterol Hepatol 5: 1190 1194.

18. Sinha A, Tekkis PP, Neale KF, Phillips RKS, Clark SK (2010) Risk factors predicting intra-abdominal desmoids in familial adenomatous polyposis: a single centre experience. Tech Coloproctol 14: 141-146.

19. Sinha A, Burns EM, Latchford A, Clark SK (2018) Risk of desmoid formation after laparoscopic versus open colectomy and ileorectal anastomosis for familial adenomatous polyposis. BJS Open 2: 452-455.

20. Clark SK, Neale KF, Landgrebe JC, Phillips RK (1999) Desmoid tumours complicating familial adenomatous polyposis. Br J Surg 86: 1185-1189.

21. Bertario L, Russo A, Sala P, Eboli M, Giarola M, et al. (2001) Genotype and phenotype factors as determinants of desmoid tumors in patients with familial adenomatous polyposis. Int J Cancer 95: 102-107.
22. Sturt NJ, Gallagher MC, Bassett P, Philp CR, Neale KF, et al. (2004) Evidence for genetic predisposition to desmoid tumours in familial adenomatous polyposis independent of the germline APC mutation. Gut 53: 1832-1836.

23. Heiskanen I, Jarvinen HJ (1996) Occurrence of desmoid tumours in familial adenomatous polyposis and results of treatment. Int J Colorectal Dis 11: 157-162

24. Elayi E, Manilich E, Church J (2009) Polishing the crystal ball: knowing genotype improves ability to predict desmoid disease in patients with familial adenomatous polyposis. Dis Colon Rectum 52: 1762-1766. [Crossref]

25. Vitellaro M, Sala P, Signoroni S, Radice P, Fortuzzi S, et al. (2014) Risk of desmoid tumours after open and laparoscopic colectomy in patients with familial adenomatous polyposis. Br J Surg 101: 558-565.

26. Nieuwenhuis MH, Lefevre JH, Bülow S, Järvinen H, Bertario L, et al. (2011) Family history, surgery, and APC mutation are risk factors for desmoid tumors in familial adenomatous polyposis: an international cohort study. Dis Colon Rectum 54: 12291234.

27. Gurbuz AK, Giardiello FM, Petersen GM (1994) Desmoid tumours in familia adenomatous polyposis. Gut 35 : 377-381

28. Caspari R, Olschwang S, Friedl W, Mandl M, Boisson C, et al. (1995) Familia adenomatous polyposis: Desmoid tumours and lack of ophthalmic lesions (CHRPE) associated with APC mutations beyond codon 1444. Hum Mol Genet 4: 337-340.

29. Davies DR, Armstrong JG, Thakker N, Horner K, Guy SP, et al. (1995) Severe gardner syndrome in families with mutations restricted to a specific region of the APC gene. $A m$ J Hum Genet 57: 1151-1158.

30. Slowik V, Attard T, Dai H, Shah R, Septer S (2015) Desmoid tumors complicating Familial Adenomatous Polyposis: a meta-analysis mutation spectrum of affected individuals. BMC Gastroenterol 15: 84-89.

31. Nieuwenhuis MH, De Vos Tot Nederveen Cappel W, Botma A (2008) Desmoid tumors in a Dutch cohort of patients with familial adenomatous polyposis. Clin Gastroenterol Hepatol 6: 215-219.

32. Campos FG, Araújo SE, Melani AG, Pandini LC, Nahas SC (2011) Surgical outcomes of laparoscopic colorectal resections for familial adenomatous polyposis. Surg Laparosc Endosc Percutan Tech 21: 327-333.

33. Campos FG, Perez RO, Imperiale AR, Seid VE, Nahas SC (2009) Surgical treatment of familial adenomatous polyposis: ileorectal anastomosis or restorative proctolectomy? Arq Gastroenterol 46: 294-299.

34. Vogel J CJ, LaGuardia L (2005) Minimally invasive pouch surgery predisposes to desmoid tumor formation in patients with familial adenomatous polyposis. In: The American Society of Colon and Rectal Surgeons Annual Meeting Abstracts, April 30May 5, 2005, Philadelphia, Pennsylvania. Philadelphia: Dis. Colon Rectum 662.

35. Walter T, Zhenzhen Wang C, Guillaud O, Cotte E, Pasquer A, et al. (2017) Management of desmoid tumours: A large national database of familial adenomatous patients shows a link to colectomy modalities and low efficacy of medical treatments. United European Gastroenterol J 5: 735-741.

36. Xie M, Chen Y, Wei W, He X, Li X, et al. (2020) Does ileoanal pouch surgery increase the risk of desmoid in patients with familial adenomatous polyposis? Int $J$ Colorectal Dis 35: 1599-1605.

37. Campos FG, Real Martinez CA, Monteiro de Camargo MG, Cesconetto DM, Nahas SC (2018) Laparoscopic versus open restorative proctocolectomy for familial adenomatous polyposis. J Laparoendosc Adv Surg Tech A 28: 47-52.

38. Sarvepalli S, Burke CA, Monachese M, Lopez R, Leach BH (2018) Web-Based mode for predicting time to surgery in young patients with familial adenomatous polyposis: an internally validated study. Am J Gastroenterol 113: 1881-1890.

39. Ueno H, Kobayashi H, Konishi T, Ishida F, Yamaguchi T, et al. (2016) Prevalence of laparoscopic surgical treatment and its clinical outcomes in patients with familia adenomatous polyposis in Japan. Int J Clin Oncol 21: 713-722. [Crossref]

40. Gupta S, Provenzale D, Llor X, Halverson AL, Grady W, et al. (2019) NCCN Guideline Insights: Genetic/Familial high-risk assessment: Colorectal, Version 2. J Natl Comp Canc Netw 17: 1032-1041.

Copyright: (C)2021 Campos FG. This is an open-access article distributed under the terms of the Creative Commons Attribution License, which permits unrestricted use, distribution, and reproduction in any medium, provided the original author and source are credited. 